'incorporated into future meta-analytical reviews.' ${ }^{2}$ A co-author of Roberts et al's letter to the editor (Cipriani) was also a co-author on this publication by Girlanda et al.

Ultimately, although we agree that the results of observational studies certainly support a role for lithium in suicide prevention, we feel that there is a clear need for more randomised trials evaluating its efficacy in preventing death by suicide. The substantial effect of a single trial highlights the tenuousness of findings regarding lithium in RCTs. Fortunately, a brief search of clinicaltrials.gov suggests that there is a large trial of lithium for suicide prevention underway (NCT01928446) and another trial that was recently completed (NCT01134731). Notably, a third trial was prematurely terminated (NCT00520026).

1 Riblet N, Shiner B, Young-Xu Y, Watts B. Strategies to prevent death by suicide: meta-analysis of randomised controlled trials. Br J Psychiatry 2017; 210: $396-402$

2 Girlanda F, Cipriani A, Agrimi E, Appino M, Barichello A, Beneduce R, et al Effectiveness of lithium in subjects with treatment-resistant depression and suicide risk: results and lessons of an underpowered randomised clinical trial. BMC Research Notes 2014; 7: 1-8.

3 Avins AL, Cherkin DC, Sherman KJ, Goldberg H, Pressman A. Should we reconsider the routine use of placebo controls in clinical research? Trials 2012; 13: 44 .

Natalie B. v. Riblet, Brian Shiner, Veterans Affairs Medical Center, White River Junction, Vermont, Geisel School of Medicine at Dartmouth, Hanover, New Hampshire, and The Dartmouth Institute for Health Policy and Clinical Practice, Hanover, New Hampshire; Bradley v. Watts, Veterans Affairs Medical Center, White River Junction, Vermont, and Geisel School of Medicine at Dartmouth, Hanover, New Hampshire, USA. Email: Natalie.BV.Riblet@dartmouth.edu

doi: 10.1192/bjp.211.6.396a

\section{Where is the argument for the conceptual slippery slope?}

I do concur with the position laid down by Brendan Kelly ${ }^{1}$ in commentary on the paper by Verhofstadt et $a l^{2}$ and his conclusion that 'we should not kill our patients'. However, one argument he has surprisingly not used is that of a 'slippery slope'. In particular, Beauchamp \& Childress ${ }^{3}$ specify two versions of this argument. The psychological-sociological one is well-known and is often cited as an argument against euthanasia. However, the conceptual slippery slope is by far the more dangerous and is exemplified here so succinctly. In Verhofstadt et al we have 'unbearable suffering' as a concept leading almost effortlessly and uncritically to the euthanasia of psychiatric patients who have no terminal disease. What is so shocking is that this is no sterile philosophical debate: it is in action in a European country and has led to patient deaths. This subjugation demonstrates the biggest risk in the euthanasia debate and should be actively resisted.

1 Kelly B. Invited commentary on: When unbearable suffering incites psychiatric patients to request euthanasia. Br J Psychiatry 2017; 211: 248-9.

2 Verhofstadt M, Thienpont L, Peters G-JY. When unbearable suffering incites psychiatric patients to request euthanasia: qualitative study. $\mathrm{Br} J$ Psychiatry 2017; 211: 238-45.

3 Beauchamp TL, Childress JF. Principles of Biomedical Ethics (4th edn). Oxford University Press, 1984

John M. Clifford, Consultant Psychiatrist, Betsi Cadwaladr University Health Board North Wales. Email: jmc123@yahoo.com

doi: 10.1192/bjp.211.6.397

Author's reply: I am very grateful to Dr Clifford for his letter. $\mathrm{He}$ is entirely correct to highlight the slippery slope. There are several slippery slopes here. Will the practice of euthanasia on the basis of suffering resulting from mental illness alone expand to less severe forms of mental illness, to earlier mental illness and to people without mental illness themselves but who experience substantial suffering as a result of mental illness in someone else (e.g. a family member)? The reason why I did not present the slippery slope argument initially was because the argument can, ironically, become a slippery slope itself, as skilled rhetoricians invoke all kinds of unlikely speculative scenarios with substantial emotional power, but limited practical relevance. Nonetheless, Dr Clifford's point is clearly right and I am especially pleased that he agrees with the central point of my commentary: we should not kill our patients.

Brendan D. Kelly, Professor of Psychiatry, Trinity College Dublin, Trinity Centre for Health Sciences, Tallaght Hospital, Dublin, Ireland. Email: brendan.kelly@tcd.ie

doi: 10.1192/bjp.211.6.397a

Authors' reply: Given that a recent trend analysis ${ }^{1}$ revealed an increase in instances of euthanasia of people with psychiatric disorders since the Belgian law on euthanasia came into effect in 2002 (despite unresolved matters of great concern), Dr Clifford's call not to ignore the potential risks of euthanasia legislation and practice is indeed essential. Since legalised euthanasia affects directly involved actors as well as healthcare systems and (inter)national societies, discussion of slippery slope arguments is necessary to stay alert and prevent ethically unacceptable acts from being accepted.

At the same time, it is important to safeguard against these discussions becoming purely philosophical, uncorroborated or even leading to a slippery slope fallacy, as might be the case if they are not based on scientific evidence. Hence, it is striking that 15 years after Belgium introduced its euthanasia law, euthanasia among psychiatric patients is still underexamined. Our own study $^{2,3}$ has concentrated on the reality of clinical euthanasia practice in Belgium and finding ways of improving its transparency and quality.

In an effort to outline this reality, we would like to react to Dr Clifford's assumption that unbearable suffering as a concept might 'lead almost effortlessly and uncritically to euthanasia'. As we stated in the introduction to our paper, ${ }^{2}$ unbearable suffering is a necessary but not a sufficient condition for granting euthanasia requests in Belgium (other conditions being the competent patient repeatedly making a voluntary and well-considered request, and suffering being rooted in an incurable medical illness without prospect of improvement ${ }^{4}$ ). Furthermore, for patients who are not terminally ill, the Belgian euthanasia law stipulates the specific legal requirement of due care that two additional independent physicians, one of whom is specialised in the patient's disorder, must be involved in careful assessment and evaluation of all the legal requirements. Hence, in the context of psychiatric patients requesting euthanasia, consultations with at least one psychiatrist are mandatory.

Our study ${ }^{2,3}$ focused on just one of the key criteria, unbearable suffering, as it represents the most subjective and indeterminate criterion in granting euthanasia requests in the absence of an overarching solid definition and psychiatric assessment tool. In order to contribute to vigilance regarding euthanasia practice, especially concerning psychiatric patients, who are a particularly vulnerable group, the assessment of key criteria such as unbearable suffering should be undertaken as comprehensively and accurately as possible.

It is precisely this scientific involvement that might inform both the slippery slope discussion and the questioning of euthanasia as an end-of-life option on grounds of these arguments. In light of 
the grave concerns and potential dangers concerning the clinical practice of euthanasia, we strongly believe in scientific evidence as important in informing the juridical, philosophical, political, societal and ethical arguments in this debate. This provides a sound basis both to legitimately question euthanasia and provide sufficient built-in safeguards to protect against potential abuses.

1 Dierickx S, Deliens L, Cohen J, Chambaere K. Euthanasia for people with psychiatric disorders or dementia in Belgium: analysis of officially reported cases. BMC Psychiatry 2017; 17: 203

2 Verhofstadt $M$, Thienpont L, Peters G-JY. When unbearable suffering incites psychiatric patients to request euthanasia: qualitative study. $\mathrm{Br} J$ Psychiatry 2017; 211: 238-45.

3 Dees $M$, Vernooij-Dassen $M$, Dekkers $W$, van Weel $C$. Unbearable suffering of patients with a request for euthanasia or physician-assisted suicide: an integrative review. Psychooncology 2010; 19: 339-52.

4 Ministry of Justice. Law on euthanasia of May 28, 2002 [in Dutch and French], Belgian Official Gazette, 2002; 22 June (http://www.npzl.be/files/ 107a_B3_wet_euthanasie.pdf).

M. Verhofstadt, End-of-Life Care Research Group, Vrije Universiteit Brussel (VUB) and Ghent University, Belgium; L. Thienpont, Co-founder of and psychiatrist at Vonkel (an end-of-life consultation centre), Ghent, Belgium; G.-J. Y. Peters, Vonkel (an end-of-life consultation centre), Ghent, Belgium; G.-J. Y. Peters,
Department of Methodology and Statistics, Faculty of Psychology and Education Science, Open University of the Netherlands, Heerlen, The Netherlands; K. Chambaere, End-of-Life Care Research Group, Vrije Universiteit Brussel (VUB) \& Ghent University, Belgium. Email: monica.verhofstadt@gmail.com

doi: $10.1192 / \mathrm{bjp} .211 .6 .397 \mathrm{~b}$

\section{The Pool judgment has not changed the law of expert evidence}

We are concerned that the editorial by Series \& Herring ${ }^{1}$ is likely falsely to give readers the impression that the Pool judgment represents a change in the law of expert evidence. The judgment has not changed the law in any way. And we would advise doctors who work, or wish to work, as experts should read the detailed analysis of the current law concerning the definition, in law, of expertise recently published in BJPsych Advances. ${ }^{2}$ This includes a review of the seminal cases, and also some other recent relevant judgments, none of which is referred to in the editorial. Psychiatrists undertaking expert witness practice should also refer to the Royal College of Psychiatrists' College Report CR193, ${ }^{3}$ soon to be amended after discussions with professional and regulatory authorities so as to make the law as clear as possible to experts.

1 Series $\mathrm{H}$, Herring J. Doctor in court: what do lawyers really need from doctors, and what can doctors learn from lawyers? Br J Psychiatry 2017; 211: 135-6.

2 Rix K, Haycroft A, Eastman N. Danger in deep water or just ripples in the pool: has the Pool judgment changed the law on expert evidence? BJPsych Adv 2017; 23: 347-57.

3 Rix K, Eastman N, Adshead G. Responsibilities of Psychiatrists Who Provide Expert Opinion to Courts and Tribunals (College Report CR193). Royal College of Psychiatrists, 2015.

Keith J. B. Rix, Honorary Consultant Forensic Psychiatrist, Norfolk and Suffolk NHS Foundation Trust, Visiting Professor of Medical Jurisprudence, School of Medicine, University of Chester; Nigel Eastman, Barrister-at-Law and Emeritus Professor of Law and Ethics in Psychiatry and Honorary Consultant Forensic Psychiatrist, St George's University of London; Anthony Haycroft, Barrister-at-Law, Serjeants Inn Chambers; Gwen Adshead, Forensic Psychiatrist and Psychotherapist, Southern Health Foundation Trust and Central \& North West London NHS Foundation Trust. Email: keith@drkeithrix.co.uk

doi: 10.1192/bjp.211.6.398

Authors' reply: We are grateful to Dr Rix and colleagues for pointing out to those who might misread our editorial ${ }^{1}$ that the Pool case has not changed the law of expert evidence, although we find it difficult to see how our brief reference to the case of Pool could be seen as misleading. They refer to their own very helpful analysis of recent case law on expert evidence in the September issue of BJPsych Advances, ${ }^{2}$ which, unfortunately, had not been published at the time our editorial went to press.

Readers who would like a full and scholarly account of the law on expert evidence are referred to Hodgkinson \& James, ${ }^{3}$ although even the most recent edition (2015) was not able to include discussion of Squire and Pool. We look forward with much interest not only to the publication of Rix et al's further article in Advances, but also to the revision of CR193, the College's guidance on the responsibilities of experts. All of us who give expert evidence are of course also required to take note of the relevant GMC guidance. ${ }^{4}$

1 Series $\mathrm{H}$, Herring J. Doctor in court: what do lawyers really need from doctors, and what can doctors learn from lawyers? Br J Psychiatry 2017; 211: 135-6.

2 Rix K, Haycroft A, Eastman N. Danger in deep water or just ripples in the pool: has the Pool judgment changed the law on expert evidence? BJPsych Advances 2017; 23: 347-57.

3 Hodgkinson T, James M. Expert Evidence: Law and Practice (4th edn). Sweet and Maxwell, 2015.

4 General Medical Council. Giving Evidence as an Expert Witness. GMC, 2017 (http://www.gmc-uk.org/guidance/ethical_guidance/21193.asp).

Hugh Series, Oxford Health NHS Foundation Trust and Faculty of Law, University of Oxford, Oxford, UK; Jonathan Herring, Faculty of Law, University of Oxford, Oxford, UK. Email: hugh.series@oxep.co.uk

doi: 10.1192/bjp.211.6.398a

\section{Conflating sexual orientation and gender identity}

It is ironic that an editorial which highlights the lack of knowledge of lesbian, gay, bisexual and transgender (LGBT) issues among healthcare professionals should open with a sentence that conflates sexual orientation with gender identity. ${ }^{1}$ Using 'heterosexual' as a contrast to LGBT is inaccurate, as any number of trans heterosexual individuals could attest to. In their discussion of Miranda-Mendizábal et al's paper, ${ }^{2}$ Meader \& Chan make it clear that the paper only covers LGB youth, and that differing sexual orientations within this group may lead to differing experiences; however, in the rest of their editorial 'LGBT youth' is treated as a monolithic entity. For example, Public Health England has two toolkits on suicide prevention in sexual minority groups, one for LGB individuals and one for transgender individuals, in recognition of the different needs of these groups (www.gov.uk/ government/publications/preventing-suicide-lesbian-gay-andbisexual-young-people), rather than a single LGBT toolkit as suggested in the editorial.

It is also perhaps disappointing that the first suggestion of why transgender young people have a greater risk of suicidality is 'higher rates of stigma'. Although this is undoubtedly important, there is increasing evidence that supporting transgender young people to live and present as their gender identity improves mental health outcomes. For example, Olson et al found that transgender children who were supported in their gender identities had rates of depression the same as their cisgender peers, rather than the much higher rates of depression previously reported for transgender children living as their birth-assigned gender. ${ }^{3}$ In this context, the waiting times for gender identity clinics (GICs) should be highlighted. For many in the UK, this is more than a year: for example, the Tavistock GIC currently gives a waiting time of 14 months from referral to first appointment (https://gic.nhs.uk/appointments/waiting-times). In fact, many 